INDO GLOBAL JOURNAL OF

PHARMACEUTICAL SCIENCES

ISSN 2249- 1023

\title{
Herbal Medicine Guazuma ulmifolia: A Review on its Traditional Uses, Phytochemistry and Pharmacology
}

\author{
Neha Shekhawat ${ }^{*}$, Sonal Gupta, Sheel Singh \\ Department of Biotechnology, K.L. Mehta Dayanad College for Women, NIT-3, B.K. Chowk, Faridabad, Haryana 121001, India \\ Address for Correspondance: Neha Shekhawat, nehnishu85@gmail.com ; sonal85gupta@gmail.com ; drsheelsingh6@gmail.com
}

Keywords

Antibacterial;

Antifungal; Anti-

inflammatory;

Antioxidant; Anti-

tumor; Antiviral;

Guazuma ulmifolia;

Mutamba.

Conference Proceedings: International Conference on Advances in Plant and Microbial Biotechnology (PMB2017); JIIT, Noida: February 02-04, 2017
ABSTRACT: Guazuma ulmifolia Lam. (Mutamba) is one of the most useful traditional medicinal plant in India. Each part of the Mutamba tree has some medicinal property that is commercially utilizable. During the last five decades, apart from the chemistry of the Mutamba compounds, considerable progress has been realized regarding the biological activity and medicinal applications of Mutamba. The extracts and metabolites of Guazuma particularly those from leaves and bark possess several useful bioactive compounds and recently additional data are available on relevance of these compounds in the various biological activities including antibacterial, antiviral, antifungal, anti-inflammatory, anti-secretory, anti-tumor and anti-oxidation. It contains important phyto-constituents such as proanthocyanidins, epicatechins, kaurenoic acid, farnesol, caryophyllene, friedlene, sitosterol, alkaloids tannins and phenols. It is therefore, considered as a valuable source of unique natural products for development of medicines against various diseases and for the development of industrial products. (C) 2016 iGlobal Research and Publishing Foundation. All rights reserved.

Indo Global Journal of Pharmaceutical Sciences( ISSN 22491023 ; CODEN- IGJPAI; NLM ID: 101610675) indexed and abstracted in EMBASE(Elsevier), SCIRUS(Elsevier),CABI, CAB Abstracts, Chemical Abstract Services(CAS), American Chemical Society(ACS), Index Copernicus, EBSCO, DOAJ, Google Scholar and many more. For further details, visit http://iglobaljournal.com 